\title{
THE ESTIMATION OF DESMOSTEROL AND CHOLESTEROL IN PLASMA
}

\author{
BY \\ L. G. WHITBY*, R. G. GOLD†, E. G. KITCHIN, AND H. A. FLEMING \\ From the John Bonnett Clinical Laboratories, Addenbrooke's Hospital, Cambridge and the Regional Cardiac Unit, \\ Papworth Hospital, Cambs. \\ Received June 28, 1963
}

Desmosterol (24-dehydrocholesterol) is the immediate precursor of cholesterol in the biosynthesis of the latter compound. The structures of these two sterols are very similar, and desmosterol interferes with many of the colorimetric methods used for estimating plasma cholesterol levels. Normally, desmosterol is not present in plasma in significant amounts, but in patients treated with triparanol, which inhibits the conversion of desmosterol to cholesterol, considerable quantities of desmosterol may be detected (Frantz, Mobberley, and Schroepfer, 1960; Avigan et al., 1960a, b; Steinberg, Avigan, and Feigelson, 1960, 1961).

Triparanol was used therapeutically because of its ability to reduce plasma cholesterol levels, but, when studying the effects of treatment with this drug, it was shown (Frantz et al., 1960; Avigan et al., 1960a; Steinberg et al., 1960) that misleading results were obtained if the only sterol estimation consisted of the measurement, at a single wavelength (in the region $620-660 \mathrm{~m} \mu$ ), of the colour developed in the Liebermann-Burchard reaction. Methods were described (Frantz et al., 1960; Avigan et al., 1960b; Hollander, Chobanian, and Wilkins, 1960) that could be used for estimating the content of cholesterol and desmosterol in specimens of plasma containing both these sterols, but, for various reasons which will be discussed, these methods failed to gain general acceptance, or were open to criticism. In the absence of a convenient method for estimating desmosterol and cholesterol in blood, reports continued to appear (Oille, 1961 ; Jepson, 1962) about patients in whom the laboratory control of triparanol treatment had consisted solely of the measurement of the Liebermann-Burchard colour in the region $620-660 \mathrm{~m} \mu$; the results of such studies cannot be accurately interpreted, since cholesterol and desmosterol both show marked but different chromogenicity under these conditions; this means that the single colorimetric reading in this wavelength region cannot be used to measure either the total plasma sterol level or the plasma cholesterol concentration when significant amounts of desmosterol are present in the sample.

Triparanol was withdrawn by the manufacturers in 1962 because several serious side-effects had been reported (Laughlin and Carey, 1962; Perry et al., 1962; Kirby et al., 1962). It is, however, possible that other drugs will be submitted for clinical trial with a mode of action similar to triparanol and, for the proper assessment of such drugs, it will be necessary to measure plasma levels of both desmosterol and cholesterol. This paper describes a simple colorimetric method for the separate determination of these two sterols in single samples of plasma. The method was used to investigate the response of 32 patients to treatment with triparanol, and it will be shown that, because patients did not respond uniformly to such treatment, measurement of the individual plasma sterol levels

* Present address: Royal Infirmary, Edinburgh.

$\uparrow$ Present address: Brompton Hospital, London S.W.3. 
provided more exact information about the response of each patient than could have been derived solely from the estimation of the total plasma sterols.

\section{METHODS}

Estimation of Cholesterol and Desmosterol. The method of sterol determination was very similar to Kenny's (1952) procedure for cholesterol, which is itself a modification of Bloor's (1917) technique. Significant points of departure were the use of $0.2 \mathrm{ml}$. samples of plasma, which were extracted with $10 \mathrm{ml}$. ethanol-ether mixture, and the development of the Liebermann-Burchard colour in subdued daylight at room temperature. The time-course for the development of the colour was determined, using solutions of cholesterol and desmosterol in chloroform, and the absorption spectra of the products were measured at various times in a Beckman DK 2 ratio recording spectrophotometer. On the basis of these experiments, the conditions for making routine determinations in a photometric colorimeter were selected, and readings were made with an Ilford 608 filter at exactly 6 minutes, and with an Ilford 621 filter at exactly 16 minutes after the addition of sulphuric acid to each sample. There was sufficient interval between these two measurements on an individual sample to allow analyses to be performed in batches, and readings were made at points on the colour-development curves where the intensity was changing slowly with time.

The spectra of the Liebermann-Burchard derivatives of cholesterol and desmosterol 16 minutes after the start of colour development are very similar below $500 \mathrm{~m} \mu$; the Ilford 621 filter has a wide transmission band in the 400-500 $\mathrm{m} \mu$ region and, with this filter, it was found that cholesterol and desmosterol gave equivalent results at this time. The spectra of the Liebermann-Burchard derivatives of these two sterols are different in the 550-700 $\mathrm{m} \mu$ region; for measurements in this region of the spectrum an Ilford 608 filter (which transmits light of $630 \mathrm{~m} \mu$ and longer wavelength) was selected and, with this filter, desmosterol developed 69.8 per cent (S.E.M. $\pm 0.8 \% ; 17$ determinations) of the colour yielded by an equal amount of cholesterol when measurements were made 6 minutes after the start of colour development. From these observations the amounts of cholesterol and desmosterol in mixtures of the two sterols, or in plasma samples, were calculated from the following equations:

$$
\begin{array}{ll}
\text { (1) } \mathrm{R}_{621}=C+D ; & \text { (2) } \mathrm{R}_{608}=C+0 \cdot 70 D \text {, }
\end{array}
$$

where $C$ and $D$ were the concentrations of cholesterol and desmosterol and $\mathbf{R}_{621}$ and $\mathbf{R}_{608}$ the apparent concentrations of cholesterol, obtained with the respective Ilford filters, in terms of the standard sterol solutions analysed with the particular batch of samples.

Analyses of mixtures prepared from solutions of pure cholesterol and desmosterol in chloroform gave quantitative recoveries of the individual sterols. The reproducibility of readings made with the Ilford 608 and 621 filters was determined by duplicating analyses on several specimens of plasma; the duplicated analyses, read with the Ilford 608 filter, agreed with a root mean square difference of 3.0 per cent and the same series of duplicated analyses, read with the Ilford 621 filter, agreed with a root mean square difference of 3.6 per cent (77 duplicated analyses). These results are comparable with the reproducibility of cholesterol analyses reported by Morris (1959), using the technique of Trinder (1952), which Morris regarded as the most satisfactory of the various methods he assessed.

The upper limit of normal for plasma cholesterol, as estimated by the technique employed in this investigation, is $250 \mathrm{mg} . / 100 \mathrm{ml}$.

Selection of Patients. 32 patients ( 20 men, 12 women; age-range 30 to 76 years) took part in the investigation: 30 had ischæmic heart disease of varying grades of severity, with a history of angina and an abnormal electrocardiogram at rest; the other 2 had tuberous xanthomatosis, with no evidence of cardiovascular disease and a normal electrocardiogram. The principal clinical diagnoses are summarized in the Table.

A full clinical examination, chest radiograph, and electrocardiogram were carried out on each patient before triparanol was prescribed, and clinical examination was repeated at frequent intervals during the period of investigation, with further radiographs and electrocardiograms as dictated by each patient's condition. Before treatment three plasma cholesterol estimations were made: specimens were collected from patients in hospital in the fasting state, but from out patients they were collected under uniform conditions of dietary intake and at the same time of day on each occasion. All patients (except Case 2) had pretreatment plasma cholesterol levels of $280 \mathrm{mg}$. $/ 100 \mathrm{ml}$. or greater. Further plasma samples were examined at approximately two- to four-weekly intervals.

The dose of triparanol used throughout this investigation was $250 \mathrm{mg}$. daily. If other forms of treatment were being administered to patients (e.g. anticoagulants, coronary vasodilators, dietary modification), these 
TABLE

Details of Response of 32 Patients to Treatment with Triparanol

\begin{tabular}{|c|c|c|c|c|c|c|c|c|c|c|}
\hline \multirow[b]{3}{*}{ Case* } & \multirow[b]{3}{*}{$\begin{array}{l}\text { Age } \\
\text { (yr.) }\end{array}$} & \multirow[b]{3}{*}{ Diagnosis $\dagger$} & \multirow{3}{*}{$\begin{array}{l}\text { L.ength of } \\
\text { treatment } \\
\text { (days) }\end{array}$} & \multirow{3}{*}{$\begin{array}{c}\text { Average } \\
\text { control } \\
\text { cholesterol } \\
\text { (mg./100 } \\
\text { ml.) }\end{array}$} & \multicolumn{6}{|c|}{ Treatment period } \\
\hline & & & & & \multicolumn{2}{|c|}{ Total sterol } & \multicolumn{2}{|c|}{ Cholesterol } & \multicolumn{2}{|c|}{ Desmosterol } \\
\hline & & & & & $\begin{array}{c}\text { Average } \\
\text { mg. } / 100 \mathrm{ml}\end{array}$ & $\begin{array}{c}\text { Change } \\
\text { relative } \\
\text { to control } \\
(\%)\end{array}$ & $\begin{array}{c}\text { Average } \\
\mathrm{mg} . / 100 \mathrm{ml}\end{array}$ & $\begin{array}{c}\text { Change } \\
\text { relative } \\
\text { to control } \\
(\%)\end{array}$ & $\begin{array}{l}\text { Maximum } \\
\text { con- } \\
\text { centration } \\
\text { mg. } / 100 \mathrm{ml}\end{array}$ & $\begin{array}{l}\text { Per cent } \\
\text { of total } \\
\text { sterols in } \\
\text { same } \\
\text { specimen }\end{array}$ \\
\hline $\begin{array}{l}1 \\
2 \\
3 \\
4\end{array}$ & $\begin{array}{l}55 \\
68 \\
54 \\
67\end{array}$ & $\begin{array}{l}\text { Myocardial infarct } \\
\text { Myocardial infarct } \\
\text { I.H.D. } \\
\text { Myocardial infarct, malignant }\end{array}$ & $\begin{array}{l}225 \\
183 \\
133\end{array}$ & $\begin{array}{l}415 \\
235 \\
370\end{array}$ & $\begin{array}{l}365 \\
190 \\
275\end{array}$ & $\begin{array}{l}-12 \\
-19 \\
-26\end{array}$ & $\begin{array}{l}335 \\
120 \\
235\end{array}$ & $\begin{array}{l}-19 \\
-49 \\
-36\end{array}$ & $\begin{array}{l}55 \\
70 \\
45\end{array}$ & $\begin{array}{l}16 \\
37 \\
16\end{array}$ \\
\hline 5 & 35 & $\begin{array}{l}\text { hypertension } \\
\text { Tuberous xanthomatosis }\end{array}$ & $\begin{array}{l}180 \\
287\end{array}$ & $\begin{array}{l}355 \\
485\end{array}$ & $\begin{array}{l}315 \\
565\end{array}$ & $\begin{array}{l}-11 \\
+16\end{array}$ & $\begin{array}{l}235 \\
435\end{array}$ & $\begin{array}{l}-34 \\
-10\end{array}$ & $\begin{array}{l}105 \\
255\end{array}$ & $\begin{array}{l}33 \\
49\end{array}$ \\
\hline 6 & $\begin{array}{l}66 \\
48\end{array}$ & $\begin{array}{l}\text { 1.H.D., xanthelasmata, } \\
\text { pulmonary tuberculosis } \\
\text { I.H.D., peripheral vascular }\end{array}$ & 238 & 280 & 285 & +2 & 255 & -9 & 65 & 22 \\
\hline & 61 & $\begin{array}{l}\text { disease, tuberous } \\
\text { xanthomatosis }\end{array}$ & 364 & 440 & 385 & -12 & 310 & -30 & 180 & 44 \\
\hline $\begin{array}{r}9 \\
10 \\
11 \\
12\end{array}$ & $\begin{array}{l}63 \\
58 \\
30 \\
34\end{array}$ & $\begin{array}{l}\text { Myocardial infarct, aortic } \\
\text { embolus, diabetes } \\
\text { I.H.D., hypertension } \\
\text { Myocardial infarct } \\
\text { Myocardial infarct } \\
\text { Myocardial infarct, diabetes, }\end{array}$ & $\begin{array}{l}200 \\
149 \\
295 \\
285\end{array}$ & $\begin{array}{l}340 \\
290 \\
325 \\
310\end{array}$ & $\begin{array}{l}290 \\
260 \\
310 \\
270\end{array}$ & $\begin{array}{l}-15 \\
-10 \\
-5 \\
-13\end{array}$ & $\begin{array}{l}245 \\
195 \\
240 \\
260\end{array}$ & $\begin{array}{l}-28 \\
-33 \\
-26 \\
-16\end{array}$ & $\begin{array}{r}80 \\
95 \\
125 \\
45\end{array}$ & $\begin{array}{l}28 \\
37 \\
37 \\
16\end{array}$ \\
\hline $\begin{array}{l}13 \\
14 \\
15 \\
16 \\
17 \\
18 \\
19\end{array}$ & $\begin{array}{l}69 \\
49 \\
51 \\
58 \\
55 \\
64 \\
69\end{array}$ & $\begin{array}{l}\text { Myocardial infarct, diabetes, } \\
\text { nephrotic syndrome } \\
\text { Myocardial infarct } \\
\text { Tuberous xanthomatosis } \\
\text { I.H.D., carotid occlusion } \\
\text { I.H.D., hypertension } \\
\text { I.H.D., hypertension } \\
\text { I.H.D. } \\
\text { I.H. hypertension. }\end{array}$ & $\begin{array}{r}87 \\
421 \\
56 \\
261 \\
98 \\
280 \\
495\end{array}$ & $\begin{array}{l}460 \\
330 \\
460 \\
320 \\
320 \\
410 \\
290\end{array}$ & $\begin{array}{l}370 \\
300 \\
915 \\
295 \\
275 \\
280 \\
295\end{array}$ & $\begin{array}{l}-20 \\
-9 \\
+99 \\
-8 \\
-14 \\
-32 \\
+2\end{array}$ & $\begin{array}{l}305 \\
200 \\
610 \\
275 \\
235 \\
250 \\
285\end{array}$ & $\begin{array}{l}-34 \\
-39 \\
+33 \\
-14 \\
-27 \\
-39 \\
-2\end{array}$ & $\begin{array}{r}85 \\
155 \\
445 \\
35 \\
50 \\
75 \\
25\end{array}$ & $\begin{array}{r}23 \\
46 \\
45 \\
10 \\
18 \\
28 \\
9\end{array}$ \\
\hline $\begin{array}{l}20 \\
21 \\
22 \\
23 \\
24\end{array}$ & $\begin{array}{l}59 \\
60 \\
61 \\
60 \\
55\end{array}$ & $\begin{array}{l}\text { pernicious anæmia } \\
\text { I.H.D., hypertension } \\
\text { I.H.D. } \\
\text { I.H.D., left ventricular failure } \\
\text { I.H.D., hypochromic anæmia } \\
\text { I.H.D., diabetes, myxœedema, }\end{array}$ & $\begin{array}{l}168 \\
219 \\
149 \\
447 \\
343\end{array}$ & $\begin{array}{l}375 \\
320 \\
345 \\
380 \\
605\end{array}$ & $\begin{array}{l}400 \\
240 \\
305 \\
325 \\
560\end{array}$ & $\begin{array}{l}+7 \\
-25 \\
-12 \\
-14 \\
-7\end{array}$ & $\begin{array}{l}370 \\
225 \\
300 \\
250 \\
465\end{array}$ & $\begin{array}{l}-1 \\
-30 \\
-13 \\
-34 \\
-23\end{array}$ & $\begin{array}{r}85 \\
65 \\
25 \\
155 \\
185\end{array}$ & $\begin{array}{r}23 \\
27 \\
8 \\
47 \\
33\end{array}$ \\
\hline $\begin{array}{l}25 \\
26 \\
27 \\
28 \\
29 \\
30 \\
31 \\
32\end{array}$ & $\begin{array}{l}57 \\
55 \\
65 \\
64 \\
55 \\
66 \\
54 \\
76\end{array}$ & $\begin{array}{l}\text { peripheral vascular disease } \\
\text { I.H.D., hypertension } \\
\text { Myocardial infarct } \\
\text { I.H.D., hypertension } \\
\text { I.H.D., hypertension } \\
\text { Myocardial infarct } \\
\text { l.H.D. } \\
\text { I.H.D. } \\
\text { Myocardial infarct }\end{array}$ & $\begin{array}{r}195 \\
228 \\
308 \\
108 \\
89 \\
284 \\
99 \\
252 \\
133\end{array}$ & $\begin{array}{l}420 \\
395 \\
330 \\
435 \\
390 \\
395 \\
375 \\
305 \\
335\end{array}$ & $\begin{array}{l}365 \\
300 \\
315 \\
390 \\
315 \\
395 \\
320 \\
295 \\
320\end{array}$ & $\begin{array}{l}-13 \\
-24 \\
-5 \\
-10 \\
-19 \\
0 \\
-15 \\
-3 \\
-4\end{array}$ & $\begin{array}{l}270 \\
250 \\
265 \\
370 \\
290 \\
345 \\
295 \\
250 \\
285\end{array}$ & $\begin{array}{l}-36 \\
-37 \\
-20 \\
-15 \\
-26 \\
-13 \\
-21 \\
-18 \\
-15\end{array}$ & $\begin{array}{r}150 \\
65 \\
105 \\
40 \\
40 \\
175 \\
25 \\
120 \\
50\end{array}$ & $\begin{array}{r}41 \\
23 \\
34 \\
9 \\
13 \\
43 \\
7 \\
7 \\
38 \\
17\end{array}$ \\
\hline
\end{tabular}

* Cases 1-20 inclusive were men; Cases 21-32 were women.

$\dagger$ I.H.D. = Ischæmic heart disease.

were continued unaltered during the investigation and throughout the period of follow-up, after triparanol treatment was stopped. Duration of treatment with triparanol varied from 56 to 495 days.

\section{RESULTS}

Details of the individual responses of the 32 patients are shown in the Table. Mean plasma cholesterol levels in the control period ranged from 235 to $605 \mathrm{mg} . / 100 \mathrm{ml}$. The fall in the mean level of total plasma sterols during treatment ranged from 0 to 32 per cent of the corresponding mean control levels. In 5 patients the total plasma sterols rose during treatment, the percentage rise being small, however, except in 2 of the 3 patients with tuberous xanthomatosis (Cases 5 and 14). The average response to triparanol treatment for the whole series was a fall of 7 per cent in the total plasma sterol level.

The fall in plasma cholesterol ranged from 1 to 49 per cent of the control level, but in one patient (Case 14) the plasma cholesterol level rose by 33 per cent; the average for the whole series was a fall of 22 per cent in the plasma cholesterol level during treatment with triparanol. The maximum concentration of desmosterol reached during treatment ranged from 25 to $445 \mathrm{mg}$. $/ 100 \mathrm{ml}$., representing 7 to 49 (average 27) per cent of the total plasma sterols in the corresponding specimens. The response of any individual patient to triparanol could not be predicted. No relation was found 


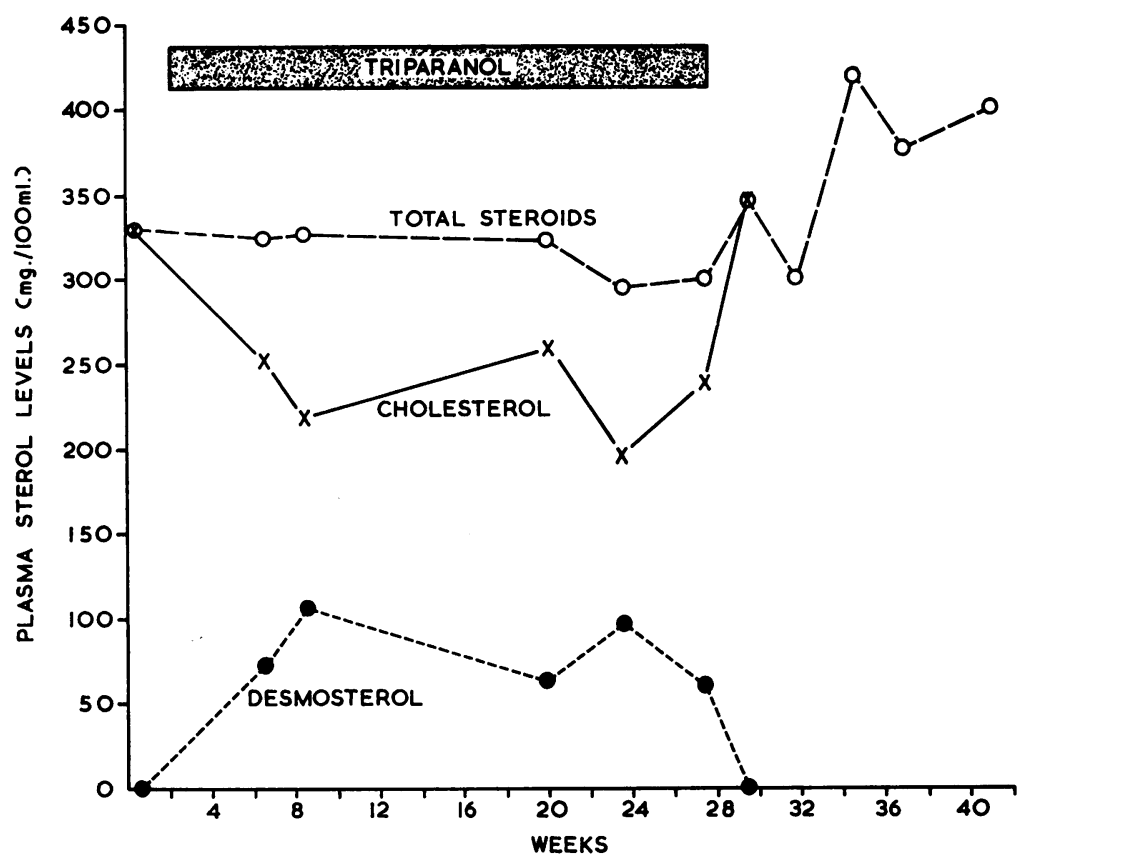

FIG. 1.-Case 4, showing the common type of response to triparanol therapy. Cholesterol is moderately reduced but total sterols only slightly reduced, due to desmosterol accumulation.

between the plasma cholesterol level before treatment and the appearance of desmosterol in the plasma during treatment, except in the patients with tuberous xanthomatosis, in whom desmosterol levels at times exceeded 40 per cent of the total plasma sterols.

The common type of response to treatment with triparanol is shown in Fig. 1 (Case 4). In these patients a moderate fall in plasma cholesterol level occurred, but the fall in total plasma sterols was less marked because of the appearance of desmosterol in the plasma. In other patients (e.g. Case 18), desmosterol could be detected but the falls in plasma cholesterol and total sterol levels were slight or absent; such lack of response was not due to failure to take triparanol.

Case 14, a patient with tuberous xanthomatosis but without previous evidence of ischæmic heart disease, responded very differently. Seven weeks after starting triparanol he felt unwell, and complained of anginal pain and generalized pruritus. One week later fresh eruptive xanthomata had appeared, but other clinical findings and the electrocardiogram were unchanged. Triparanol was discontinued and, within four weeks, the xanthomata had reverted to their pretreatment state, itching had stopped, and the patient felt well again. Fig. 2 shows the results of plasma sterol analyses in this patient during and after the period of treatment with triparanol.

\section{Discussion}

The findings in the present investigation are comparable with those from other trials in which the response of patients to treatment with triparanol has been assessed by measuring both plasma cholesterol and desmosterol levels (Steinberg et al., 1961 ; Jose, Learoyd, and Peak, 1961 ; Blankenhorn and Kuzma, 1961; Doak, Nicholson, and North, 1962). The majority of patients respond to the administration of triparanol, as shown in Fig. 1, but some patients show no response, at least at the dose level ( $250 \mathrm{mg}$. daily) prescribed in this series.

The variability of response to triparanol means that the results of treatment with this drug cannot be assessed solely from measurements of the Liebermann-Burchard colour in the region $620-660 \mathrm{~m} \mu$, 


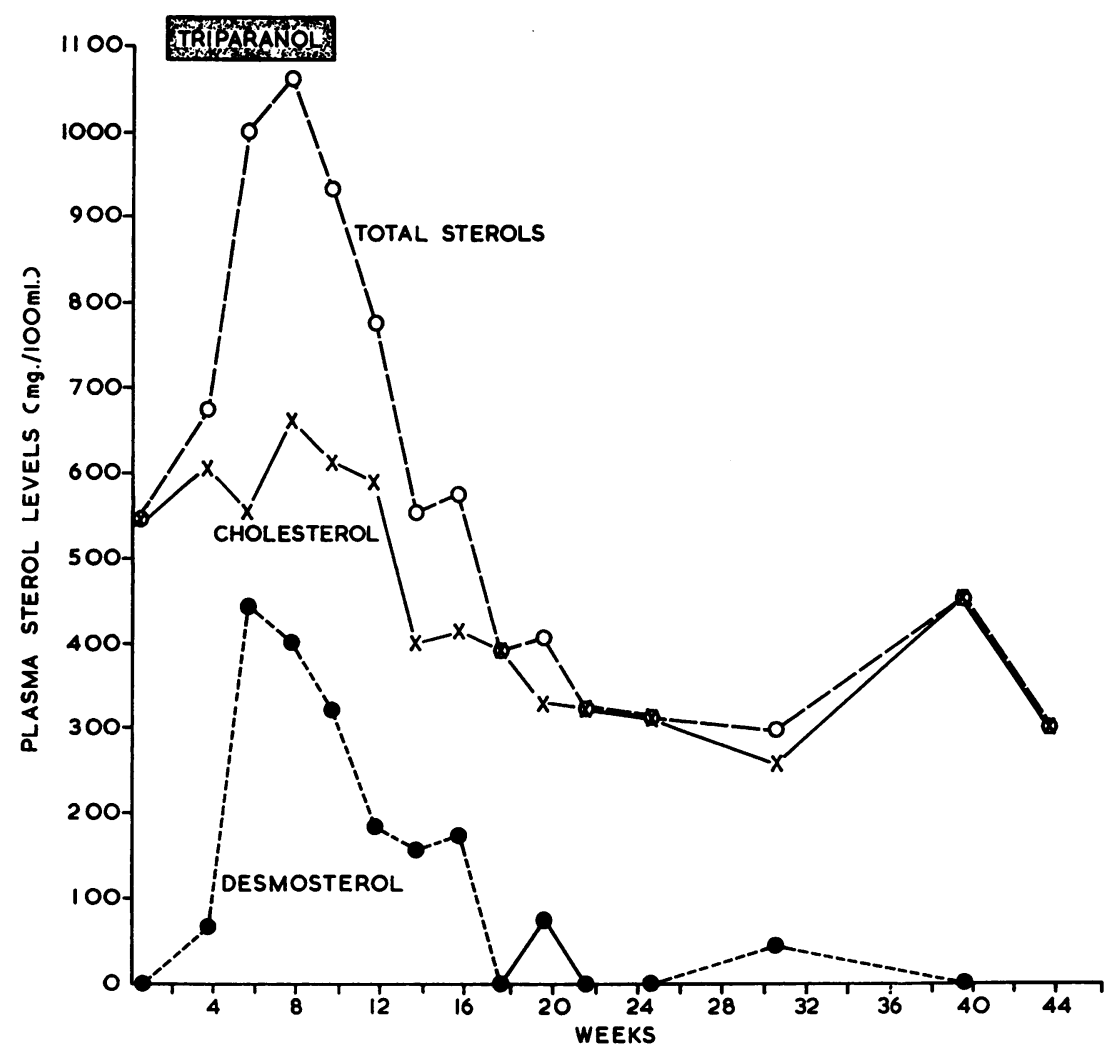

FIG. 2.-Case 14, showing marked increase in cholesterol and total sterols during triparanol therapy with the appearance of large amounts of desmosterol in the plasma.

since it cannot be assumed for any individual patient that desmosterol will constitute a definite percentage of the total sterols in the blood, and interpretations of results that rely on such an assumption (Jepson, 1962) are open to criticism. In general, it is true to say that the plasma cholesterol level will be lower and the total sterol concentration higher than the results of the LiebermannBurchard reaction indicate when measure ments are made only in this region of the spectrum, but the findings presented in the Table show how variable is the individual response and confirm the results of others (Steinberg et al., 1961 ; Blankenhorn and Kuzma, 1961) where the levels of cholesterol and desmosterol have been separately determined.

In some patients treatment with triparanol resulted in the appearance of large amounts of desmosterol in the plasma. In these, and especially where there was also a marked rise in the total plasma sterols (e.g. Cases 5 and 14), results of treatment would have been even more liable to misinterpretation, if based solely on measurements of the Liebermann-Burchard colour in the 620 $660 \mathrm{~m} \mu$ region. Case 14 is the second recorded instance of the development of fresh xanthomata in a patient as a result of triparanol treatment but, in the patient described by Schiller and Armstrong (1962), the plasma sterol analyses were subject to the above criticism. If only a single biochemical determination is to be performed, a technique that measures the total plasma sterols must be adopted (Avigan and Steinberg, 1962).

Several methods have been developed for estimating the individual concentrations of desmosterol and cholesterol, when present together in blood. Two different chromatographic techniques have been published (Frantz et al., 1960; Avigan et al., 1960b). These methods separate cholesterol from 
desmosterol and allow the individual concentrations of these sterols to be measured directly, but Avigan et al. (1960b) were unable to confirm the separations claimed by Frantz et al. (1960), and the chromatographic method described by Avigan et al. (1960b) has not been applied to blood successfully. Both techniques are laborious, and the most promising chromatographic procedure is gasliquid chromatography (VandenHeuvel, Sweeley, and Horning, 1960). This was used qualitatively (Steinberg et al., 1961; Herndon and Siperstein, 1963) to confirm that cholesterol and desmosterol were the only sterols present in the serum of a patient treated with triparanol, but the conditions for performing this analysis quantitatively by gas-liquid chromatography have not yet been published, and Horning et al. (1963) have recently reviewed the practical problems connected with the quantitative determination of steroids in biological materials by this technique.

Non-chromatographic methods are, at present, the techniques most readily applicable on a routine basis. All these procedures require two separate measurements, one of which is the intensity of the Liebermann-Burchard colour in the 620-660 $\mathrm{m} \mu$ region, but they differ among themselves in the technique used for determining the total sterol content of the specimen. Hollander et al. (1960) estimated total plasma sterols either gravimetrically by precipitation with digitonin, or colorimetrically by applying the anthrone reaction to the digitonin precipitate; Frantz et al. (1960) used the Zak colour reaction (Zlatkis, Zak, and Boyle, 1953), with which they reported that cholesterol and desmosterol gave practically identical colour yields.

Both the anthrone and Zak reactions were investigated at the start of the present work. The anthrone reaction proved very tedious when applied to large numbers of specimens, and the Zak reaction gave variably high results, a shortcoming previously observed by Fürst and Lange (1954) and by Morris (1959). Because of this shortcoming, calculations based on the Zak reaction resulted in a variable overestimate of the proportion of desmosterol contributing to the total plasma sterols, as well as a variable overestimate of the total plasma sterol levels. Furthermore, the relative behaviour of cholesterol and desmosterol in the Zak reaction showed considerable disagreement between the three series in which it was assessed (Frantz et al., 1960; Jose et al., 1961; Sachs and Wolfman, 1961). This makes difficult the accurate interpretation of the results of investigations into the action of triparanol where biochemical control has been wholly or in part dependent on the Zak reaction (e.g. Owen Williams, Gaddie, and Singh, 1962).

Avigan et al. (1960b) devised a simpler procedure, employing solely the Liebermann-Burchard reaction, to obtain the information necessary to calculate the separate contributions due to cholesterol and desmosterol when present together in blood. Colorimetric readings were made at two different times and at two different wavelengths in a single specimen. This procedure was slightly modified by Steinberg et al. (1961), and the modified technique was employed by Blankenhorn and Kuzma (1961). The present method is similar in principle to the procedures of Avigan et al. (1960b) and Steinberg et al. (1961), and shares with them the following advantages over the other non-chromatographic methods available: it depends on a single analytical procedure rather than on two unrelated techniques, which means that it minimizes technical errors; it is economical of samples and reagents, and it is less laborious.

Many techniques are available for carrying out the Liebermann-Burchard reaction, but the method of Kenny (1952), as employed here, is considered more suitable for the present purpose than the procedures selected by Avigan et al. (1960b) and by Steinberg et al. (1961). Avigan et al. (1960b) used the method of Sperry and Webb (1950), and the observations at $420 \mathrm{~m} \mu$ were therefore liable to serious interference from traces of digitonin. Other shortcomings of the Sperry and Webb technique as a routine procedure were noted by Morris (1959). Steinberg et al. (1961) used the method of Abell et al. (1952) for sterol determinations, but this technique shows poor reproducibility (Thomas and Eisenberg, 1957), when compared with the results obtained by the present method.

The use of different wavelengths of measurement in the $620-660 \mathrm{~m} \mu$ region of the spectrum by various authors accounts for the different ratios recorded for the intensity of colour developed by desmosterol and cholesterol in the Liebermann-Burchard reaction. It cannot be too strongly emphasized, therefore, that any laboratory intending to determine both plasma cholesterol and 
desmosterol levels by this colorimetric technique should itself determine the relative behaviour of these two sterols under the analytical conditions selected.

Although the method described in this paper was used in the assessment of triparanol, a drug which has been withdrawn from therapeutics, the technique may well be of value in future clinical trials since it is possible that other drugs will be developed which inhibit the biosynthesis of cholesterol at a late stage, after the formation of the sterol nucleus. In the absence of satisfactory direct methods for estimating both desmosterol and cholesterol in plasma, the procedure described in this paper offers a satisfactory means of assessing the value of such drugs in the control of hypercholesterolæmia.

\section{SUMMARY}

A colorimetric technique is described for estimating the individual concentrations of desmosterol and cholesterol in single samples of plasma, and the results obtained with this method during an investigation of the effects of triparanol treatment in 32 patients are presented.

Although triparanol has been withdrawn from therapeutics, other drugs having a similar mode of action may be developed and will then require assessment. It is shown that determinations of both desmosterol and cholesterol levels in plasma provide more complete information about the response of patients to such drugs than measurement solely of the total plasma sterol concentration.

Other methods for estimating desmosterol and cholesterol levels in plasma are discussed, and reasons are given for criticizing those investigations in which the biochemical effects of triparanol were assessed either solely in terms of the colour developed in the 620-660 $\mathrm{m} \mu$ region of the spectrum in the Liebermann-Burchard reaction, or by methods involving the use of the Zak colour reaction.

Triparanol was kindly supplied (as MER-29) by Dr. D. Mansell-Jones of Merrell National Ltd., and desmosterol (24-dehydrocholesterol) by Professor W. Klyne from the Steroid Reference Collection and by Dr. D. Mansell-Jones.

The authors also wish to express their thanks to Dr. T. R. Blohm for helpful discussions, and to Dr. L. B. Cole and Dr. C. H. Whittle for allowing several of their patients to take part in the trial.

\section{REFERENCES}

Abell, L. L., Levy, B. B., Brodie, B. B., and Kendall, F. E. (1952). A simplified method for the estimation of total cholesterol in serum and demonstration of its specificity. J. biol. Chem., 195, 357.

Avigan, J., and Steinberg, D. (1962). Deposition of desmosterol in the lesions of experimental atherosclerosis. Lancet, 1, 572.

-, Thompson, M. J., and Mosettig, E. (1960a). The mechanism of action of MER-29. Progr. cardiovasc. Dis., 2, 525.

, Troman, H. E., Thompson, M. J., and Mosettig, E. (1960b). Studies of cholesterol biosynthesis. I. The identification of desmosterol in serum and tissues of animals and man treated with MER-29. J. biol. Chem., 235, 3123.

Blankenhorn, D. H., and Kuzma, O. (1961). Acute effects of triparanol in man. Metabolism, $10,763$.

Bloor, W. R. (1917). The determination of cholesterol in blood. J. biol. Chem., $29,437$.

Doak, P. B., Nicholson, G. I., and North, J. D. K. (1962). Triparanol and nicotinic acid in the management of hypercholesterolæmia. Aust. Ann. Med., 11, 29.

Frantz, I. D., Mobberley, M. L., and Schroepfer, G. J. (1960). Effects of MER-29 on the intermediary metabolism of cholesterol. Progr. cardiovasc. Dis., 2, 511.

Fürst, V., and Lange, R. (1954). Evaluation of an acetic acid-sulphuric acid method for quantitative determination of cholesterol in serum. Scand. J. clin. Lab. Invest., 6, 60.

Herndon, J. H., and Siperstein, M. O. (1963). Desmosterol deposition in human and experimental atherosclerosis. Circulat. Res., 12, 228.

Hollander, W., Chobanian, A. V., and Wilkins, R. W. (1960). The cholesterol lowering effects of triparanol (MER29) in subjects with and without coronary artery disease. Progr. cardiovasc. Dis., $2,637$.

Horning, E. C., Maddock, K. C., Anthony, K. V., and VandenHeuvel, W. J. A. (1963). Quantitative aspects of gas chromatographic separations in biological studies. Analyt. Chem., 35, 526.

Jepson, E. M. (1962). MER-29 (triparanol) in the control of hypercholesterolæmia. Proc. roy. Soc. Med., 55, 480.

Jose, A. D., Learoyd, B., and Peak, H. (1961). The treatment of hypercholesterolæmia by MER-29. Med.J. Aust., $2,938$.

Kenny, A. P. (1952). The determination of cholesterol by the Liebermann-Burchard reaction. Biochem. J., 52, 611.

Kirby, T. J., Achor, R. W. P., Perry, H. O., and Winkelmann, R. K. (1962). Cataract formation after triparanol therapy. Arch. Ophthal. (Chic.), 68, 486.

Laughlin, R. C., and Carey, T. F. (1962). Cataracts in patients treated with triparanol. J. Amer. med. Ass., 181, 339. 
Morris, T. G. (1959). A comparison of methods for the estimation of serum cholesterol and values in random samples of populations in the 55-64 age group. J. clin. Path., 12, 518.

Oille, W. A. (1961). Serum cholesterol with triparanol (MER-29) administration. Appl. Therap., 3, 251.

Owen Williams, G. E., Gaddie, R., and Singh, S. P. (1962). Control of serum lipids by diet and triparanol (MER-29). J. Atheroscler. Res., $2,96$.

Perry, H. O., Winkelmann, R. K., Achor, R. W. P., and Kirby, T. J. (1962). Side effects of triparanol therapy. Amer. J. med. Sci., 244, 556.

Sachs, B. A., and Wolfman, L. (1961). Studies of serum desmosterol levels in hypercholesteremic subjects treated with triparanol (MER-29). Amer. J. clin. Nutr., 9, 760.

Schiller, K. F. R., and Armstrong, J. (1962). Cutaneous xanthomata complicating treatment with triparanol. Brit. med. J., 2, 1658.

Sperry, W. M., and Webb, M. (1950). A revision of the Schoenheimer-Sperry method for cholesterol determination. J. biol. Chem., 187, 97.

Steinberg, D., Avigan, J., and Feigelson, E. B. (1960). Identification of 24-dehydrocholesterol in the serum of patients treated with MER-29. Progr. cardiovasc. Dis., 2, 586.

,$--\rightarrow$, and (1961). Effects of triparanol (MER-29) on cholesterol biosynthesis and on blood sterol levels in man. J. clin. Invest., 40, 884.

Thomas, C. B., and Eisenberg, F. F. (1957). Observations on the variability of total serum cholesterol in Johns Hopkins medical students. J. chron. Dis., 6, 1.

Trinder, P. (1952). The determination of cholesterol in serum. Analyst, 77, 321.

VandenHeuvel, W. J. A., Sweeley, C. C., and Horning, E. C. (1960). Separation of steroids by gas chromatography. J. Amer. chem. Soc., 82, 3481 .

Zlatkis, A., Zak, B., and Boyle, A. J. (1953). A new method for the direct determination of serum cholesterol. J. Lab. clin. Med., 41, 486. 